\title{
Field Test and Numerical Study of a Two-Span Simply-Supported Bridge Strengthened with FRP Sheets
}

\author{
Fei WANG \\ Zhengzhou Public Utility Investment Development Group \\ Co. Ltd, Zhengzhou, China \\ E-mail: dmyan@zzu.edu.cn
}

\author{
Weiping LI \\ Zhejiang Provincial Institute of Communications Planning, \\ Design \& Research \\ Hangzhou, 310058, China
}

\author{
Junying ZENG \\ Hangzhou Bok Biotechnologies Co., Ltd \\ Hangzhou, China
}

\begin{abstract}
The application of FRP as a strengthening material in bridges have been widely accepted in recent years. To demonstrate the effectiveness of FRP sheets in concrete bridge decks with no transverse reinforcement, a two-span simply supported reinforced concrete slab with no transverse steel reinforcement was studied through both field test and numerical analysis. The structural behavior was verified with a FEM model. An externally bonded FRP laminate system is a feasible solution to upgrading the obsolete bridge to meet the current design requirement for transverse reinforcement. The load tests indicate that the FRP strengthening of the concrete bridge meets the deflection requirement stipulated in the standards. The FEM analysis generally supports the field observations from load tests. The FRP sheets improve the integrity of the overall bridge deck to a certain degree, making two halves of the bridge deck partially work together. The parapet and curb of the solid slab bridge significantly contribute to the overall stiffness of the bridge system.
\end{abstract}

Keywords-bridge; strengthening; FRP; load test; FEM model

\section{INTRODUCTION}

FRP composites are anisotropic and characterized by excellent tensile strength in the direction of the fibers. They do not exhibit yielding, but instead are elastic up to failure. FRP composites are corrosion resistant, and therefore should perform better than other construction materials in terms of weathering behavior. The addition of FRP materials to upgrade deficiencies or to strengthen structural components can save lives by preventing collapse, reduce the damage to infrastructure, and the need for their costly replacement. The retrofit with FRP materials with desirable properties provides an excellent replacement for traditional materials, such as steel jacket, to strengthen the reinforced concrete structural members. Existing studies have shown that the use of FRP materials restore or improve the column original design strength for possible axial, shear, or flexure and in some cases allow the structure to carry more load than it was designed for(Yang, 2001; Parvin and Brighton, 2014; Zomorodian, 2016).

The bridge selected for demonstration of the FRP strengthening technology is a two-span simply-supported reinforced concrete slab. The total bridge length is $36 \mathrm{ft}$
$(10.98 \mathrm{~m})$ and the edge-to-edge width of the bridge deck is $30 \mathrm{ft}(9.15 \mathrm{~m})$. This bridge represents an ideal case for the application of FRP composites since its deficiency is due primarily to a lack of transverse reinforcing steel. Based on the initial inspection, the area where the FRP was to be installed showed excellent surface conditions. A single crack extends longitudinally through the two spans along the centerline. The crack was more than 1.0 inch $(2.54 \mathrm{~cm})$ wide at some locations. There was no significant cracking elsewhere and only minor corrosion of the reinforcement was detected(Ghosh and Karbhar, 2007; Yan et al, 2010(a) and (b)). Fiber-reinforced polymer (FRP) material systems, composed of fibers embedded in a polymeric matrix, exhibit several properties suitable for their use as structural reinforcement (ACI Committee 440, 2008; Nanni, 2001; Ali et al, 2012; Peng et al, 2016).

The overall objective of the paper was to demonstrate the feasibility of externally bonding fiber reinforced polymer (FRP) reinforcement for the flexural strengthening of an existing concrete bridge structures with a wide open longitudinal crack.

\section{Non-Destructive Evaluation AND BRIDGE ANALYSIS}

\section{A. Non-Destructive Testing Results}

Based on the visual and Non-Destructive Testing (NDT) evaluation, it was determined that the superstructure is a solid concrete slab 9 in $(22.86 \mathrm{~cm})$ thick, running from pier to pier. It was longitudinally reinforced with \#10 (31.75 mm) bars spaced at 6 in $(12.7 \mathrm{~cm})$ center-to-center. No transverse reinforcement was observed. Based on the compressive tests of four cylindrical concrete cores (3in $\times 6 \mathrm{in}$ or $7.62 \mathrm{~cm} \times 15.24 \mathrm{~cm})$, the average compressive strength of the concrete was determined to be 4,100 psi $(28.27 \mathrm{MPa})$. The yield strength of the steel reinforcement was $32 \mathrm{ksi}(220.63$ $\mathrm{MPa})$ based on the tension test of one rebar. More details about the NDT testing can be found in Yan et al(2010 a and b). 


\section{B. Load Calculation Based on Non-Destructive Test Results}

According to AASHTO 3.5.1, the dead load shall include the weight of all components of the structure, appurtenances and utilities attached thereto, earth cover, wearing surface, future overlays, and planned widening. The bridge was analyzed for a design truck load condition and for a design lane load condition. The design truck load has a front axle load of $8.0 \mathrm{kips}$, a second axle load of $32.0 \mathrm{kips}$ located $14.0 \mathrm{ft}$ behind the drive axle and a rear axle load also of 32.0 kips. The rear axle load is positioned at a variable distance ranging between $14.0 \mathrm{ft}$ and $30.0 \mathrm{ft}$. A dynamic load allowance shall be considered as specified in Article 3.6.2.The calculated ultimate moment $(\mathrm{Mu}$,$) and$ shear $(\mathrm{Vu})$ resistant capacities are $353.25 \mathrm{k}-\mathrm{ft}$ and $83.71 \mathrm{kip}$, respectively. The calculated nominal moment $(\phi \mathrm{Mn}$,) and shear ( $\phi$ Vn, $)$ resistant capacities are $568.3 \mathrm{k}$-ft and 153 kips.

\section{BRIDGE STRENGTHENING}

\section{A. Objectives and Technical Approach}

FRP systems have been successfully used for seismic upgrading of concrete structures. These applications include mitigating brittle failure mechanisms such as shear failure of unconfined beam-column joints, shear failure of beams and/or columns, and lap splice failure. FRP systems have also been to confine columns to resist buckling of longitudinal steel bars. These FRP schemes increase the global displacement and energy dissipation capacities of the concrete structure, and improve its overall behavior.

The objective of the strengthening in this study is to provide the necessary transverse reinforcement. Since no reinforcement was provided in the transverse direction, minimal strengthening is needed to ensure that the transverse design moment capacity is larger or equal to the cracking moment, in order to avoid further crack openings and deterioration of the concrete due to water percolation through the cracks. In this study, a commercially available externally bonded Carbon Fiber Reinforced Polymers (CFRP) laminates were adopted to strengthen the bridge in the transverse direction by a manual wet lay-up installation technique. Before FRP installations, the longitudinal crack along the centerline of the bridge was first repaired in order to re-establish material continuity and assure no water percolation through the crack. For this purpose, the crack was sealed using an epoxy-paste and then injected with a very low viscosity resin. FRP was then applied.

The FRP laminates was designed according to ACI 440.2R-08, referred to ACI 440 thereafter. The properties of the FRP composite materials used in the design are summarized in Tab. 1. They are the guaranteed values by manufacturers.

TABLE I. Properties of CFRP Laminate Constituent

\begin{tabular}{|c|c|c|c|c|}
\hline Properties & Primer & Putty & Saturant & $\begin{array}{l}\text { High Strength } \\
\text { Carbon Fiber }\end{array}$ \\
\hline$f_{f u}^{*}, \mathrm{ksi}$ & 2.5 & 2.2 & 8.0 & 550 \\
\hline$\varepsilon_{f l}^{*}$, in $/$ in & 40 & 7.0 & 7.0 & 0.017 \\
\hline$E_{f}, \mathrm{ksi}$ & 104 & 260 & 260 & 33000 \\
\hline$t_{f}$, in. &.-- & $\cdots$ & ....-... & 0.0065 \\
\hline
\end{tabular}

The $\phi$ factors used to convert nominal strengths to design capacities were obtained as specified in AASHTO (2007) for the as-built bridge members and from ACI 440 for the strengthened members. The FRP material properties reported by manufacturers, such as the ultimate tensile strength, typically do not consider long-term exposure to environmental conditions, and should be considered as initial properties. They are modified in all design equations as in ACI 440. The FRP design modulus of elasticity is the average value as reported by the manufacturer.

\section{EXTERNAL BONDED CFRP LAMINATES}

The bond between FRP system and the existing concrete is critical, and surface preparation is essential to most applications. Any existing deterioration or corrosion of internal reinforcement must be resolved prior to installation of the FRP system. Failure to do so can result in damage to the FRP system due to delamination of the concrete substrate.

To avoid further cracking in the bridge deck, a total of five, 12 in $(30.48 \mathrm{~cm})$ wide, $28 \mathrm{ft}(8.53 \mathrm{~m})$ long, two-ply CFRP strips are required. The final design of the CFRP laminates was to evenly space five strips over the span length of $18 \mathrm{ft}(5.49 \mathrm{~m})$ and run the entire width of the slab, as shown in Fig. 1. The CFRP laminates were applied by a certified contractor in accordance to manufacturer's specification (Watson Bowman Acme Corp., 2002) (see Fig. $1(b))$. 


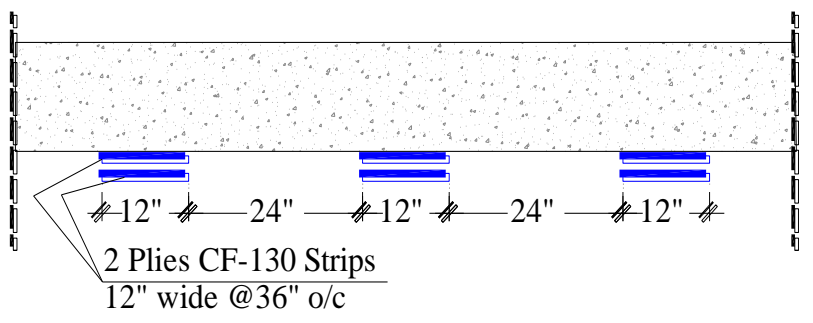

(a) Section View

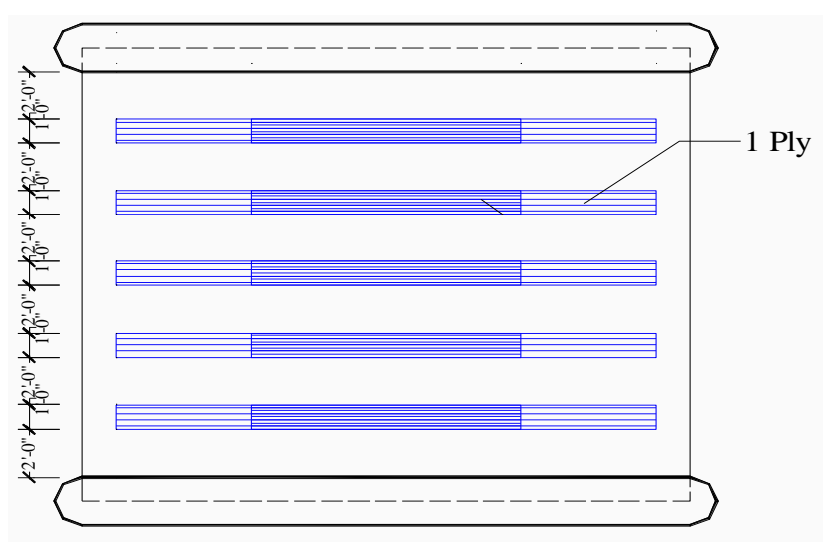

(b) Plan View

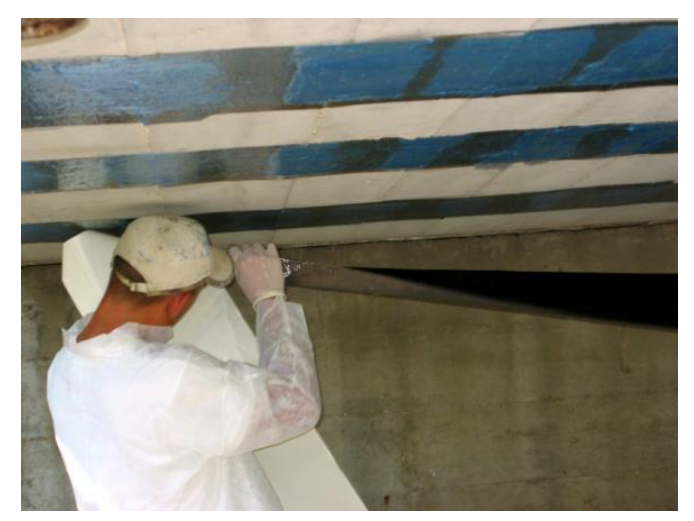

(c) Application of FRP laminates

Figure 1. Laminate locations

\section{FIELD Evaluation}

Although in-situ bridge load testing is recommended by AASHTO (2007) as an "effective means of evaluating the structural performance of a bridge," no guidelines currently exist for bridge load test protocols. In each case the load test objectives, load configuration, instrumentation type and placement, and analysis techniques are to be determined by the organization conducting the test.

In order to validate the behavior of the bridge, static load tests were performed with a dump truck. The bridge was tested under three passes of the truck: one central and two side passes as illustrated in Fig. 2. For each pass, four stops were executed with the truck having its rear axle centered over the center pier, at the quarter point, at the mid-span, and over the end pier, which were clearly marked on the asphalt pavement for the side pass.

During each stop, the truck stationed for at least two minutes before proceeding to the next location to allow stable readings. Vertical displacements were measured with eight Linear Variable Differential Transformers (LVDT as shown in) that were distributed along the traffic direction and its perpendicular direction.
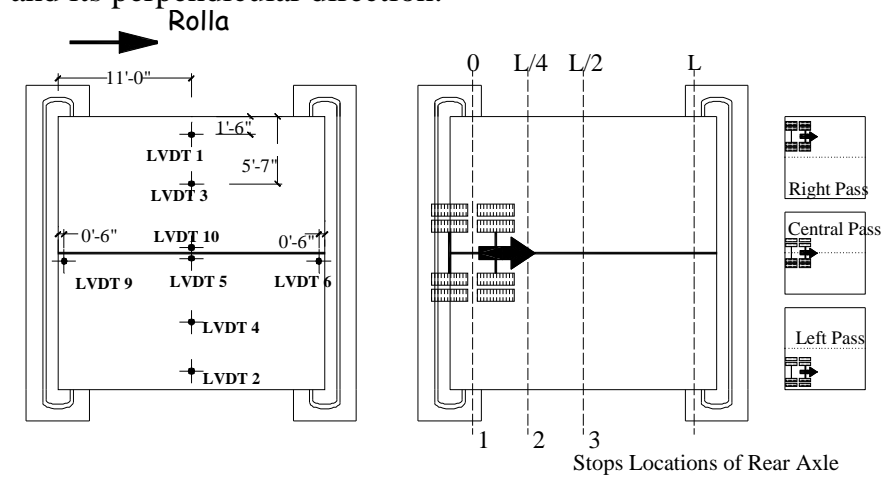

Figure 2. LVDT Locations and Stop Locations of the Truck Rear Axle

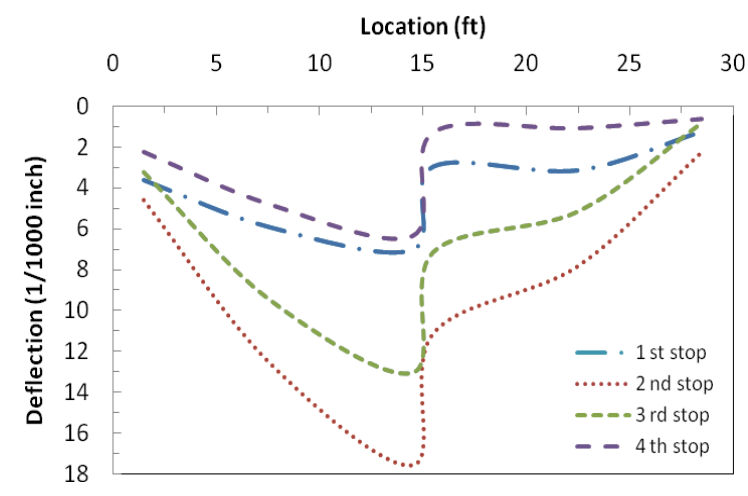

(a) Longitudinal direction

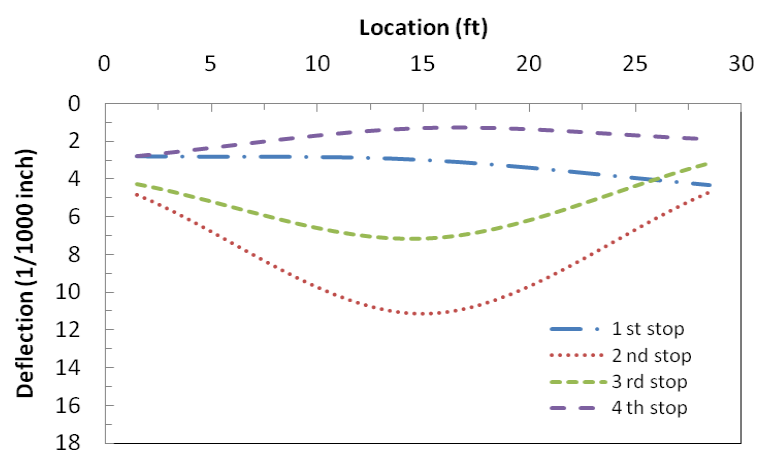

(b) Transverse direction

Figure 3. Deflection of the bridge deck

The instrumentation layout was designed to understand the deflection distribution of the bridge deck. In theory, the bridge acted symmetrically. Therefore, the instrumentation system was concentrated on one half of the bridge deck. The results of the load tests are presented in Figure 3. These 
results consistently show the discontinuity of deflection along the centerline of the bridge as a result of the longitudinal crack. This was probably the first bridge application with a significant longitudinal crack. Therefore, although an effort was made to seal the crack, the two sides of the bridge deck still did not perform as one unit. Overall, the bridge performed well in terms of the maximum deflection. In fact, the maximum deflection measured during the load test is below the allowable deflection prescribed by the 2007 AASHTO, Section 8.9.3. That is $\delta \max \leq \mathrm{L} / 800$ $=0.27 \mathrm{in}(6.86 \mathrm{~mm})$.

\section{FEM MODELING AND ANALYSIS}

To facilitate the interpretation of the test data, a linear elastic FEM of the bridge was established and analyzed using ABAQUS. An eight-node element (C3D8) was chosen to model the concrete deck. Each node has three translational degrees of freedom. The steel reinforcement was modeled as truss element, which was assumed in perfect bond with the surrounding concrete. Up to three different rebar properties may be specified.

In this study, the material properties of concrete were assumed to be isotropic and linear elastic because the applied load was within the elastic range. The modulus of elasticity of the concrete was based on the measured compressive strength obtained from the concrete core tests according to ACI 318-06, Section 8.5.1:

Each concrete element was $3.5 \mathrm{in} \times \operatorname{5in} \times 6$ in $(8.9 \mathrm{~cm} \times$ $12.7 \mathrm{~cm} \times 15.2 \mathrm{~cm}$ ). The parapet and curb on the bridge deck was modeled as an equivalent rectangular element. Two numerical models were developed in this study. The first numerical model (NM-I) represented the entire bridge deck with continuous plate elements that did not include the longitudinal crack observed on the bridge. The stress distribution under different loading conditions is shown in Fig. 4. In this case, as the test truck passed on the right or left side, only the half bridge deck on that side responded to the truck load as indicated in Fig. 2.

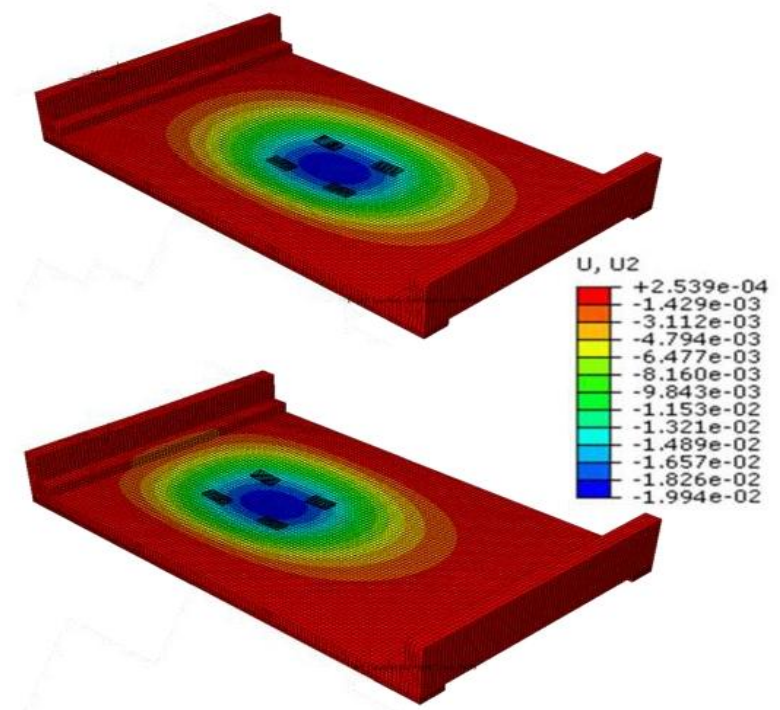

Figure 4. Deflection for central pass and right pass conditions

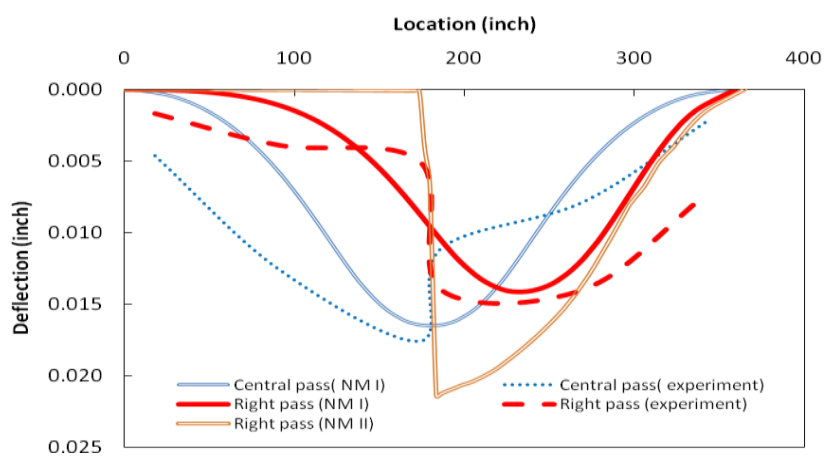

Figure 5. Numerical and experimental results

The experimental and numerical (vertical) deflections distributed along the transverse line are compared in the following figure for the central and right passes. They show a general agreement in the order of deflection. The maximum deflections obtained from the NM-I and NM-II models are smaller and greater than the experimental result, respectively. This is attributable to the difference of deck stiffness in the two cases. When crack is not present, the entire bridge deck works together, experiencing a low deflection. When crack initiates along the centerline of the bridge deck, only half of the deck supported the truck passing on that side, resulting in a greater deflection. The lateral FRP laminate will not only restrict the further development of the crack, but also improve the integrity of the bridge deck.

\section{SUMMARY}

Based on the load tests and numerical simulations, the following observations can be made:

An externally bonded FRP laminate system is a feasible solution to upgrade the obsolete bridge to meet the current design requirement for transverse reinforcement;

The load tests indicate that the FRP strengthening of the concrete bridge meets the deflection requirement stipulated in the 2007 AASHTO Specifications;

The FEM analysis generally supports the field observations from load tests. The FRP laminate improve the integrity of the overall bridge deck to a certain degree, making two halves of the bridge deck partially work together. The parapet and curb of the solid slab bridge significantly contribute to the overall stiffness of the bridge system.

Since FRP composites are designed to last for the service life of the structure, the impact of possible future renovations and modifications should be considered where the FRP is accidentally damaged. Such damage may not be observed immediately and the structure, or structural component, may remain in service until the damage is identified and the affected areas are repaired.

\section{ACKNOWLEDGEMENT}

Financial support to complete this study by National Key Technology R\&D Program No. 2012BAJ13B04 is greatly appreciated. 


\section{REFERENCES}

[1] AASHTO (2007): "Standard Specifications for Highway Bridges", 17th Edition, Published by the American Association of State Highway and Transportation Officials, Washington D.C.

[2] ACI 440.2R-08, 2008: "Guide for the Design and Construction of Externally Bonded FRP Systems for Strengthening Concrete Structures," Published by the American Concrete Institute, Farmington Hills, MI.

[3] ACI 318-02, 2002: "Building Code Requirements for Structural Concrete and Commentary (318R-02)," Published by the American Concrete Institute, Farmington Hills, MI.

[4] Ali O., Bigaud D., Ferrier E. (2012). "Comparative durability analysis of CFRP-strengthened RC highway bridges", Construction and Building Materials, 30: 629-642.

[5] Ghosh K. K., Karbhari V. M. (2007). "Evaluation of strengthening through laboratory testing of FRP rehabilitated bridge decks after inservice loading", Composite Structures, 77(2):206-222.

[6] Nanni, A. (2001), "Relevant Applications of FRP Composites in Concrete Structures," Proc., CCC 2001, Composites in Construction, Porto, Portugal, Oct. 10-12, 2001, J Figueiras, L. Juvandes and R. Furia, Eds., (invited), pp. 661-670.
[7] Parvin A. and Brighton D. (2014). "FRP Composites Strengthening of Concrete Columns under Various Loading Conditions", Polymers, 6(4), 1040-1056.

[8] Peng H., Zhang J., Shang S., Liu Y., Cai C.S. (2016). "Experimental study of flexural fatigue performance of reinforced concrete beams strengthened with prestressed CFRP plates", Engineering Structures, 127(15): 62-72.

[9] Yan D., Wu C., Li J. and Chen G.(2010a) "Inspection, analysis and loading test of a slab bridge strengthened with FRP laminates", Proceedings of 5Th International Conference on FRP Composites in Civil Engineering, Beijing, China, September 27-29.

[10] Yan D., Wu C., Li J. and Chen G.(2010b) "Strengthening Rolla Bridge with FRP laminates. Proceedings of International Symposium on Life-Cycle Performance of Bridges and Structures", June 27-29, pp442-433, Changsha, China.

[11] Yang, X. (2001), "The engineering of construction specifications for externally bonded FRP composites" Doctoral Dissertation, Department of Civil Engineering, University of Missouri-Rolla, Rolla, Missouri, $166 \mathrm{pp}$.

[12] Zomorodian M., Yang G., Belarbi A., Ayoub A. (2016), "Cracking behavior and crack width predictions of FRP strengthened RC members under tension", Engineering Structures, 125(15):313-324. 